\title{
Endogenous tidal and semilunar moulting rhythms in early juvenile shore crabs Carcinus maenas: implications for adaptation to a high intertidal habitat
}

\author{
Chaoshu Zeng*, Pere Abello**, Ernest Naylor \\ School of Ocean Sciences, University of Wales-Bangor, Menai Bridge, Anglesey LL59 5EY, United Kingdom
}

\begin{abstract}
Newly recruited early juveniles of the shore crab Carcinus maenas in North Wales are most abundant on the high intertidal of gravelly shores and, unlike adults, they do not undertake upand-down shore migration with tides. Freshly collected first and second instar juvenile crabs showed persistent circatidal rhythms of moulting when maintained in constant laboratory conditions. Peaks of moulting occurred around expected times of high tides, with few crabs moulting at other times. The circatidal moulting patterns were similar in crabs collected at different stages of the neap-spring cycle Daily monitoring of moulting in the laboratory of 23 batches of early crabs, collected from the high intertidal at 1 to $3 \mathrm{~d}$ intervals over 2 spring-neap cycles, further showed a marked circasemilunar moulting pattern superimposed on the tidal moulting rhythms. Significantly more crabs moulted within $24 \mathrm{~h}$ after collection when collected during spring tides than when collected at neaps. Moreover, the daily percentage moulting of the crabs on consecutive days after collection clearly followed the trend of predicted tidal height changes. Crabs collected on days of increasing tidal amplitude showed increasing moulting rates on the days after collection, whilst a decreasing trend of daily moulting rate was found if they were collected on days of decreasing tidal amplitude. For crabs collected at minimum neaps, when water did not reach the high intertidal even at high tides, virtually no moulting took place on the following days. Moulting at high tide, particularly during spring high tides, appears to be an adaptation to a high intertidal habitat which is only inundated at certain times during semilunar and tidal cycles. For C. maenas early juveniles, which remain in the high intertidal even when tides recede, anticipation of the rising and falling of tides through endogenous physiological programming to avoid ecdysis at the time exposed to air has clear adaptive value. The coupling of circatidal and circasemilunar moulting rhythms, and their endogenous control, reported in the present study appears to be the first demonstration of such a phenomenon in a crustacean
\end{abstract}

KEY WORDS: Tidal and semilunar moulting rhythms - Endogenous - Carcinus maenas early juvenile High intertidal habitat Adaptation

\section{INTRODUCTION}

Ecdysis, during which the entire old cuticle of an animal is shed at one time, is a critical event in the life history of a crustacean and known to be under

\footnotetext{
Present addresses:

- Seikai National Fisheries Research Institute, 49 Kokubumachi, Nagasaki-shi, Nagasaki 850-0951, Japan

E-mail: cszeng@snf.affrc.go.jp

- Institut de Ciencies del Mar (CSIC), Passeig Joan de Borbo s/n, 08039 Barcelona, Spain
}

endocrine regulation and involve extensive biochemical and physiological changes (e.g. Skinner 1985, Chang 1989, 1993, 1995, Wheatly 1997). It therefore would not be surprising if, under intensive selective pressure, endogenous mechanisms have evolved to programme the event to occur at appropriate times. Studies on the temporal patterns of moulting in crustaceans have certainly elucidated rhythms of seasonal, lunar, semilunar, and diel periodicity (see review by Conan 1985). However, despite the fact that many intertidal crustaceans exhibit physiological 
processes correlated with tidal rise and fall (see DeCoursey 1983, Naylor 1985, Palmer 1995a for reviews), it is only recently that evidence of endogenous circatidal moulting rhythms in a marine crustacean was first found (Abello et al. 1997, Zeng et al. 1997).

Carcinus maenas (L.) is a crab species widely distributed on coasts and estuaries of northwestern Europe and northeastern America (Crothers 1968, Berril 1982) and it has been recently reported spreading along US coasts (Cohen et al. 1995, Grosholz \& Ruiz 1995). Larval dispersal no doubt contributes to recent reported marginal diffusion of the species and recent research has shown that combined larval release rhythms at nocturnal high tide and inherited tidal vertical migration rhythms phased to ebb tide enhance rapid offshore dispersal of newly released zoea larvae (Zeng \& Naylor 1996a,c,d, 1997, Queiroga et al. 1997). Recruitment back to crab populations on coasts takes place at the megalopa stage, facilitated by reversed, flood-phased, upward swimming rhythms. Such tidal swimming rhythms, coupled with endogenous metamorphic moulting timed around high tides, enable settlement of first stage crabs to occur on their preferred zone in the upper shore (Zeng \& Naylor 1996b, Zeng et al. 1997). The newly settled juvenile crabs remain on the high intertidal and, unlike adults, do not undertake up-and-down shore migration with tides (Reid et al. 1993, Warman et al. 1993, pers. obs.). When tides recede and their habitat is exposed to the air, juveniles shelter under gravel, seaweed and mussel clumps, or bury in the substrate (Klein-Breteler 1976, Reid et al. 1993, Warman et al. 1993, pers. obs.).

For Carcinus maenas megalopae, it has been suggested that tidal moulting rhythms timed around high tides are adaptive in enhancing the rate of successful metamorphosis and settlement in the high intertidal (Zeng et al. 1997). Similarly, since early juveniles of the crab remain on the upper shore throughout each tidal cycle and, during ecdysis, need to absorb water for body expansion and calcium from seawater to calcify their new cuticle (Greenway 1983, 1985, Chang 1995, Wheatly 1997), they also might reasonably be expected to possess circatidal ecdysis rhythms. Furthermore, it can be hypothesized that during minimal neaps, when the high intertidal is not covered by seawater even at high tide, juvenile crabs may be inhibited from moulting for several days, thus resulting in selection for a circasemilunar moulting rhythm superimposed on the circatidal moulting pattern. The present study set out to investigate moulting in early juveniles of the crab $C$. maenas, and to assess whether it was patterned in relation to tidal and semilunar springneap cycles.

\section{MATERIALS AND METHODS}

During July to September 1995, the peak recruitment season of Carcinus maenas, early juveniles of the crab were collected at low tide from gravel and shingle high intertidal zone of the Menai Straits, North Wales, UK (53 $\left.13^{\circ} 42^{\prime \prime} \mathrm{N}, 04^{\circ} 09^{\prime} 31^{\prime \prime} \mathrm{W}\right)$. Using fine-tipped forceps, first and second instar crabs were collected carefully and placed immediately into containers filled with seawater. The crabs were then quickly transported back to the nearby laboratory and sorted, all damaged specimens being discarded.

For tidal rhythm experiments, young crabs were evenly distributed into aquaria $(40 \times 30 \times 30 \mathrm{~cm})$ at a density of no more than 100 crabs aquarium ${ }^{-1}$. The aquaria were filled with $8 \mathrm{~cm}$ of seawater from the collecting site (salinity: $34.5 \pm 0.5 \%$ ) and kept in continuous white light at a temperature of $21 \pm 1^{\circ} \mathrm{C}$, approximating that in the field in the hot summer of 1995. They were fed with Artemia nauplii and fine-chopped cooked mussel or shrimp, provided in excess at randomly determined times of the day. No substratum was provided during the experiments and water exchange took place every 1 to $2 \mathrm{~d}$ at varied times of the day. The occurrence of exuviae, as well as of newly moulted individuals, was checked every $1.5 \mathrm{~h}$ for at least $3 \mathrm{~d}$, with all exuviae and moulted crabs being removed from the aquaria after each checking. A total of 190 crabs was used in the first run of the experiment, which started on 30 July, during a period of spring tides. The second run used 183 crabs, collected on 3 August, when tide amplitude was decreasing from springs to neap. The third run was carried out with a total of 260 crabs collected on 11 August, at a time of increasing tidal amplitude toward the maximum spring.

To test whether the timing of moulting in the young crab is tidally related, periodogram analysis of the data was carried out following the methodology of Enright (1965a), as modified by Williams \& Naylor (1978), using a Turbo-Pascal (7.0) program (PERIO), cited in Aargard et al. (1995). The principle of periodogram analysis is based on repeated 'buys-ballot' form-estimates. Calculations are made of the variance of raw data points grouped in standard units over each period length being tested for. A function of this variance (usually standard deviation) is then plotted against period length to produce a graphical periodogram. High values of the periodogram statistic occur when the period under investigation approximates to the periodicity inherent in the raw data. Significant periodicity is assumed when the periodogram statistic of raw data for a given period is greater than the upper $95 \%$ confidence limit of a 'periodogram' (a regression line for which hyperbolic confidence intervals can be plotted) derived after randomizing the original data. 
In order to test whether differences in moulting frequency occurred as a function of tidal amplitude changes during semilunar spring-neap cycles, batches of 95 to 260 first and second instar juvenile crabs were collected daily or every other day from the high intertidal over 2 spring/neap cycles (from 27 July to 2 September). A total of 3098 crabs was collected for these observations and the juvenile crabs collected on different days were maintained separately in $10 \mathrm{l}$ plastic buckets (about 100 crabs bucket $^{-1}$ ) filled with $5 \mathrm{l}$ seawater. The crabs were kept under continuous bench lamp illumination and were checked several times a day for exuviae during the days after collection. During the month-long period of observations, the water temperature was between 19 and $22^{\circ} \mathrm{C}$, and salinity between 32.0 and $35.0 \%$. The daily moulting rate was calculated as a percentage of the total number of unmoulted crabs at the beginning of each day. Unlike some other crab species, the juvenile Carcinus maenas was not aggressive and hardly any cannibalism occurred during the experiments. Indeed, juvenile mortality rates were zero in most trials, and in the cases where mortality did occur it was generally lower than $3 \%$ and was taken into account by subtracting the number of dead crabs from the initial number. Other experimental procedures were the same as in the tidal rhythm experiments mentioned above.

To test whether the observed pattern of moulting frequency variations among crabs collected at different stages of spring-neap cycle was statistically significant, single-factor analysis of variance (ANOVA) was applied after dividing all of the moulting data shown in Fig. 3 into 4 categories according to the semilunar stages when those data were collected: (1) spring moulting - moulting occurred during the 3 highest spring tide days of each semilunar cycle; (2) neap moulting - moulting took place during the 3 minimal neap tide days of each semilunar cycle; (3) spring-to-neap moulting - all moulting fell between first 2 categories and was during days of decreasing tidal amplitude; (4) neap-to-spring moulting all moulting fell between first 2 categories and was during days of increasing tidal amplitude. All percentage moulting data were subjected to arcsine transformation before analysis.

The tide in the Menai Strait is typically semidiurnal with a period of approximately $12.4 \mathrm{~h}$ and maximum amplitude at spring tides of about $7.5 \mathrm{~m}$ during the study period (Menai Strait Tidal Tables, 1995-School of Ocean Sciences, University of Wales-Bangor)

\section{RESULTS}

Moulting in first and second instar crabs of Carcinus maenas showed a clear pattern of circatidal periodicity with moulting concentrated around the times of expected high tides (Fig. 1). The patterns were similar in populations of crabs collected at different stages of semilunar cycles. Fig. 1a shows the circatidal moulting pattern of a group of 190 early juvenile crabs collected during maximum spring tides. A tatal of 129 (67.9\%) of them had moulted $72 \mathrm{~h}$ after monitoring started. The peaks of moulting clearly took place at approximately the times of expected high tide, few crabs moulted around the expected times of low tide. Fig. 1b shows moulting of a group of 183 early crabs collected during spring-to-neap decreasing tidal amplitudes. Only 16 of them $(8.7 \%)$ had moulted after $72 \mathrm{~h}$ and the moulting pattern is less clear-cut than in Fig.1a. However, when moulting took place, most of them did phase with the expected times of high tide. Fig. 1c shows moulting of a group of 260 early crabs collected during a time of tidal amplitude increasing toward maximum springs. A total of 123 of them ( $47.9 \%$ ) had moulted within $72 \mathrm{~h}$, again in a less clear-cut pattern than in Fig. 1a. However, moulting was again phased with the expected times of high tide. Periodogram analysis confirmed that the moulting pattern in Fig. $1 \mathrm{a}-\mathrm{c}$ was circatidal (Fig. 2). The involvement of endogenous timing mechanisms, which synchronized the moulting, is evident since the rhythms persisted under constant laboratory conditions.

Despite the overall similarity in displaying circatidal moulting rhythms among different trials in Fig. 1, there appeared to be noticeable differences in the ratio of crabs moulted to the next stage in a unit time after collection when they were collected at different times of the spring-neap cycle (Fig. 1). This prompted further experiments to examine whether moulting was further regulated by the spring-neap cycles. For this purpose. 23 batches of early juvenile crabs (a total of 3098 individuals) were collected from the high intertidal during 2 semilunar cycles and their daily moulting frequency monitored in the laboratory. Fig. 3a shows the percentage moulting $24 \mathrm{~h}$ after collection of the 23 batches plotted against the date of collection; the predicted tidal heights (Menai Strait Tidal Table, 1995) over the sampling period are also presented. It demonstrated that moult frequency of the juvenile crab populations has a marked circasemilunar rhythmicity, with moulting concentrated during the periods of predicted increasing and maximum spring tides. The circasemilunar moulting pattern is further evident in Fig. 3b, in which all daily moulting data of Fig. 3 a are pooled based on date of moulting in relation to the days of maximum spring tides. Applying single-factor analysis after grouping all moulting data in Fig. 3 into 4 categories (1-spring moulting; 2 - neap moulting; 3 - spring-toneap moulting and 4 -neap-to-spring moulting) according to the semilunar stages when those data were 
(a)

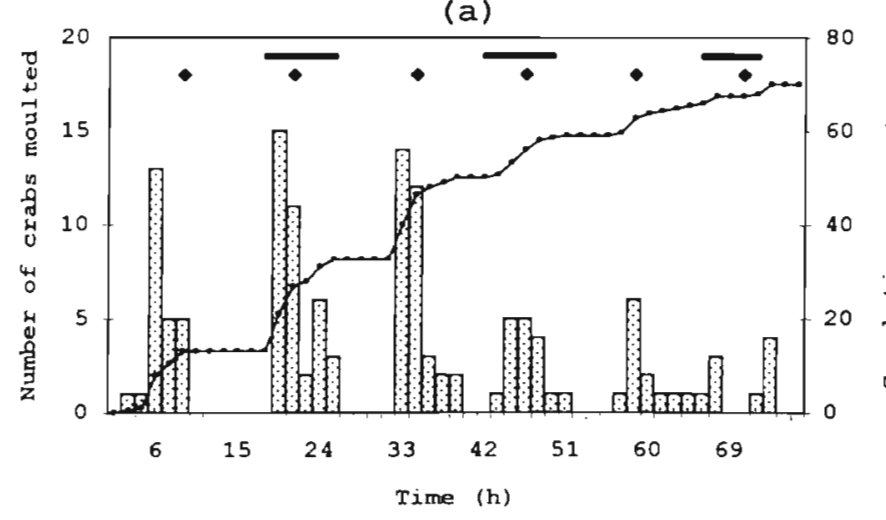

(b)
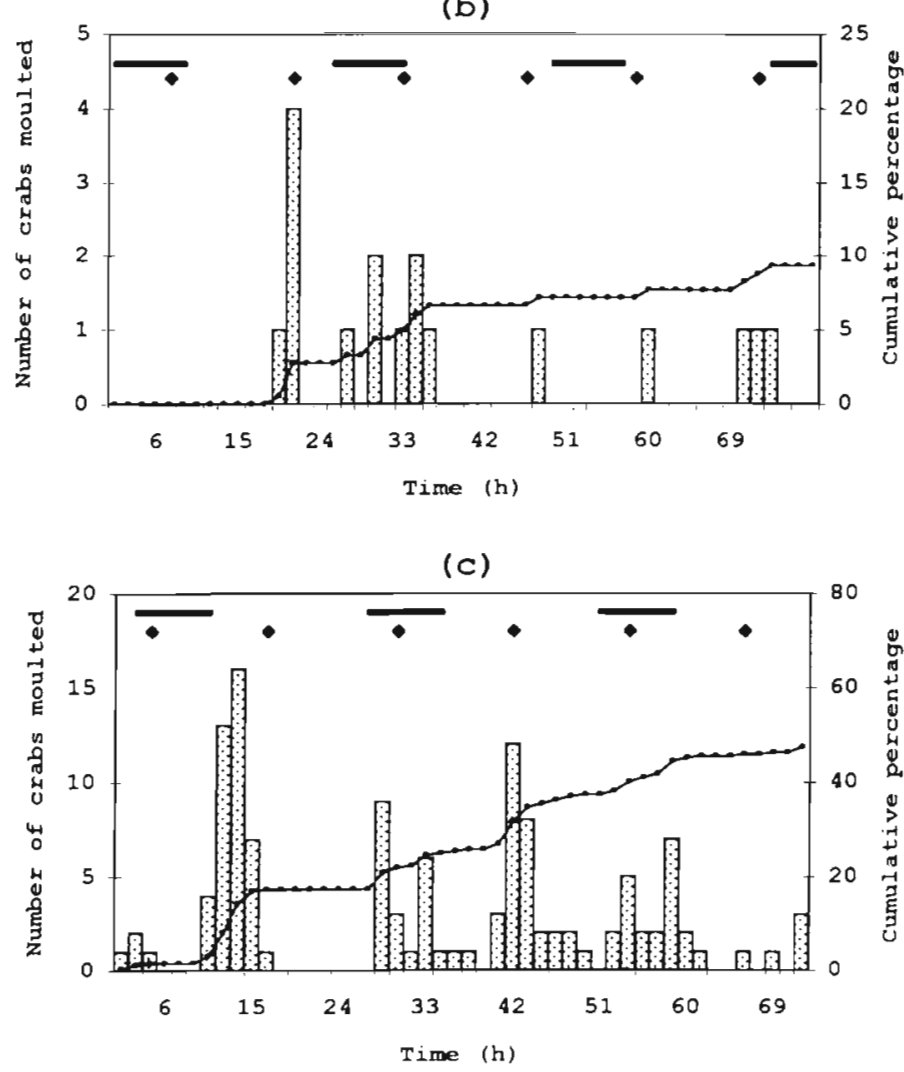

Fig. 1. Carcinus maenas. Number (histograms) and cumulative percentage moulting (lines) of freshly collected first and second instar crabs from the high intertidal at different semilunar stages that moulted to the next instar every $1.5 \mathrm{~h}$ under constant laboratory conditions. Diamonds: times of expected high tides at the collection site; solid horizantal bars: expected hours of darkness. (a) Collection made during maximum spring tide. Experiment started with a total of $190 \mathrm{crabs}$ at 03:00 h, 30 July 1995, $8 \mathrm{~h}$ after collection (high water of the day: $7.33 \mathrm{~m}$ ). (b) Collection made during spring-to-neap decreasing tidal amplitudes. Experiment started with a total of 183 crabs at 19:30 h, 3 August, soon after collection (high water of the day: $6.83 \mathrm{~m}$ ). (c) Collection made dunng a time of increasing tidal amplitude toward maximum spring tide. Experiment started with a total of 260 crabs at 19:30 h, 10 August, soon after collection (high water of the day: $7.04 \mathrm{~m}$ ) collected, confirmed that the observed pattern of moulting frequency variations among crabs collected at different stages of spring-neap cycle is very significant (1-way ANOVA: $F_{3,19}=9.23, \mathrm{p}=0.0006$ ).

The endogenous physiological programming of the semilunar moulting rhythms is further evident in Fig. 4. Daily moulting frequency of 9 representative

(a)

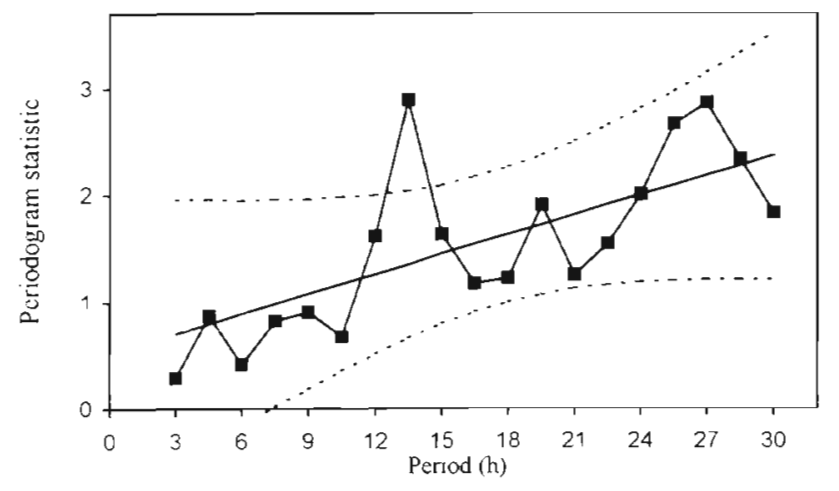

(b)

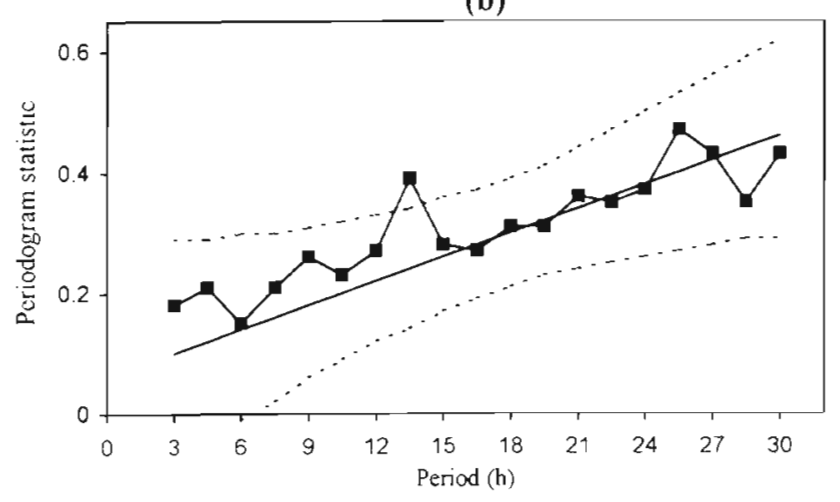

(c)

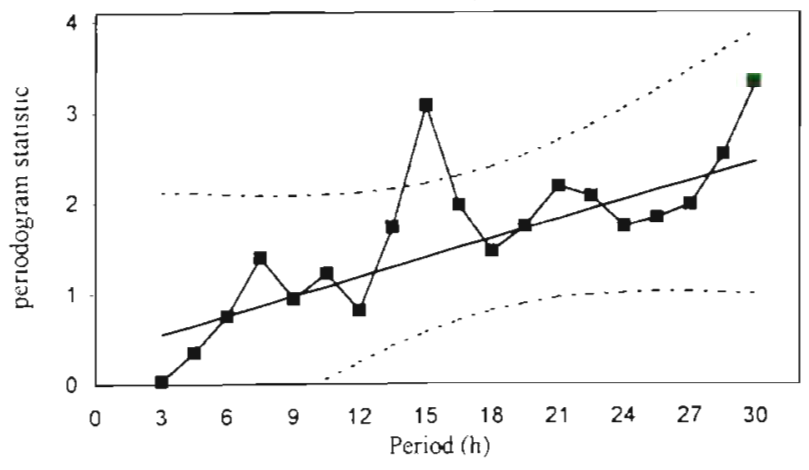

Fig. 2. Carcinus maenas. Periodogram analysis of data sets shown in Fig. 1. (a), (b), and (c) represent the periodogram statistics of Fig. $1 a, b, c$ respectively, with a peak above the upper confidence limits between 13 and $15 \mathrm{~h}$ in all cases. $95 \%$ confidence limits of the periodogram are derived after randomization of each of the original data sets (see Willams \& Naylor 1978 for further details) 
a.

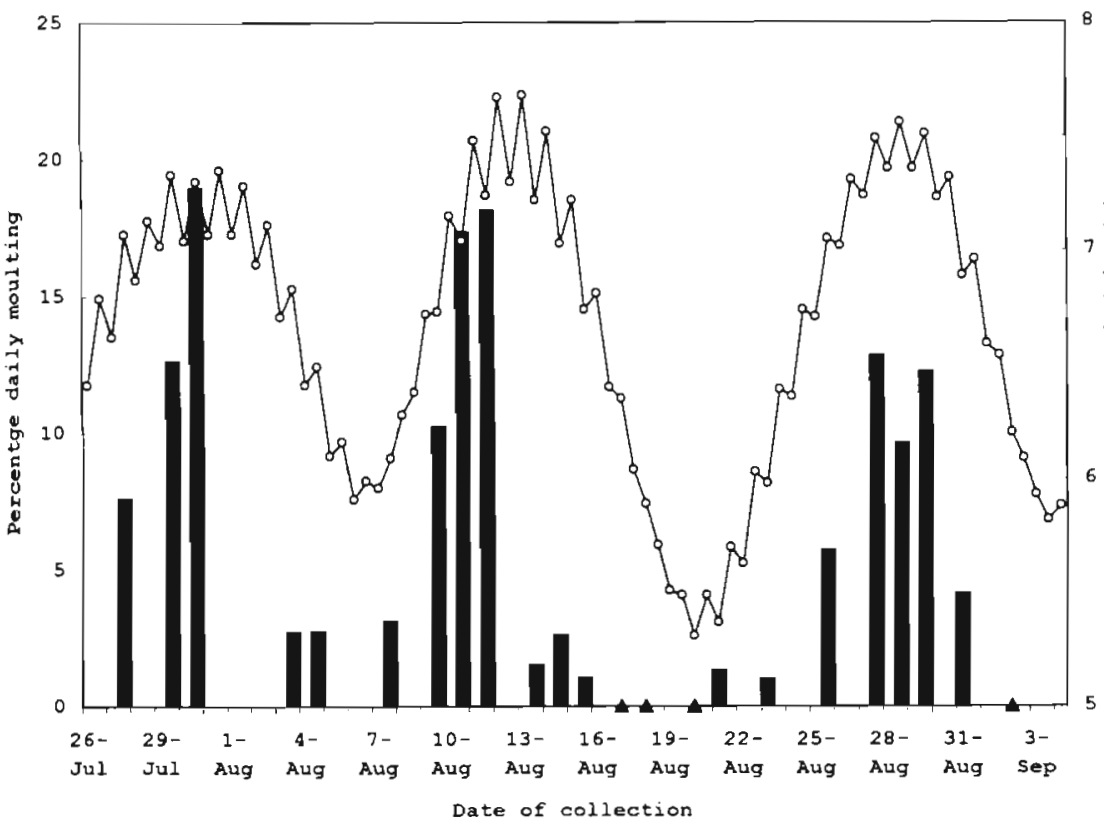

b.

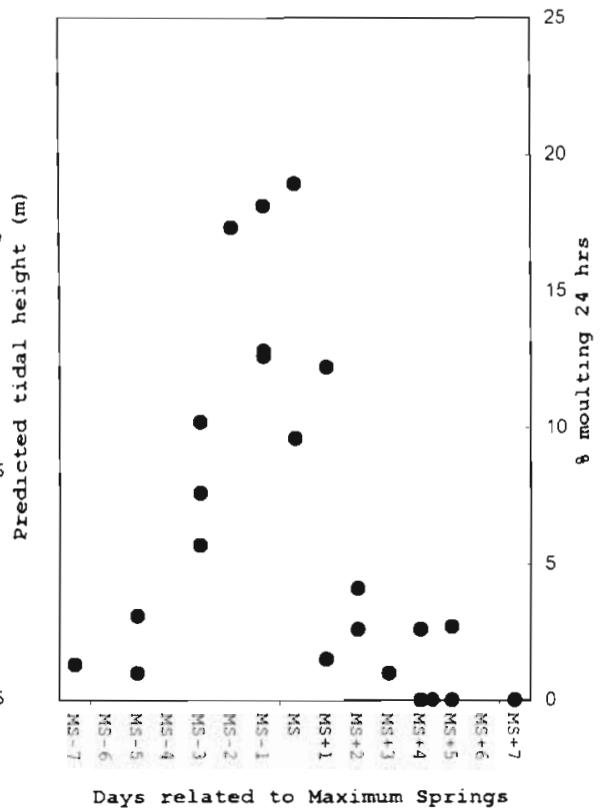

Fig. 3. Carcinus maenas. (a) Percentage moulting (histograms) $24 \mathrm{~h}$ after collection in 23 batches of 95 to 260 first and second instar crabs, freshly collected from the high intertidal at different semilunar stages between 27 July and 2 September 1995 . Line represents predicted tidal maxima over the period. Triangles on $x$-axis: days on which no moulting took place within $24 \mathrm{~h}$ of collection. (b) Daily moulting data of (a) pooled together according to the tidal status of the observing date in relation to the days of maximum spring tide of each semilunar cycle. MS: days of maximum spring tide; $M S-1$, MS+1, etc: days before and after the days of maximum spring tide, respectively

batches of crabs, collected at different stages of the spring-neap cycles at a few day intervals, is shown for 5 to 8 consecutive days in Fig. 4A. Moulting of those different batches of crabs, though kept in identical laboratory conditions, clearly followed the patterns of tidal amplitude changes associated with the semilunar cycle. When crabs were collected during neap-tospring increasing tidal amplitudes, their daily moulting frequency showed an increasing trend (Fig. 4Aa,e), whereas a reversed trend was found for those collected during spring-to-neap decreasing tidal amplitudes (Fig. 4Ac,g,h). When collection was made just before a minimal neap tide, virtually no ecdysis took place during the following days (Fig. 4Ad,i); however, when collection was made just before a maximum spring tide, peak moulting occurred for 2 or $3 \mathrm{~d}$ after collection and then decreased (Fig. 4Ab,f). The trend of moulting rate fluctuating with the tidal amplitude is emphasized in Fig. 4B, in which daily moulting frequency between 27 July and 4 September 1995 was calculated for each day by pooling together all moulting numbers available from the different crab batches for the day and then dividing by the total crab number on that day. The moulting of the crab clearly followed predicted tidal height changes, confirming peak moulting during rising and maximum spring tides.

\section{DISCUSSION}

Early juveniles of Carcinus maenas are known to occur most abundantly in the high intertidal and remain there after the tide recedes (Klein-Breteler 1976 , Hunter \& Naylor 1993, Reid et al. 1993, Warman et al. 1993). At low tides, they are normally found taking refuge among seaweed, gravel, mussel clumps or buried in the substrate (Klein-Breteler 1976, Reid et al. 1993, Warman et al. 1993, Albrecht \& Reise 1994, Thiel \& Dernedde 1994). In the present study area in North Wales, newly settled early juvenile crabs were found distributed most abundantly, sometimes in densities of tens to close to a hundred crabs per $\mathrm{m}^{2}$, in a narrow gravelly area of the upper shore (pers. abs.), where megalopae close to metamorphosis were also found aggregating in huge numbers in the surf during nocturnal spring high tides in the peak recruitment season of the crab (Zeng et al. 1997)

There is as yet no direct experimental evidence to explain why newly settled juvenile crabs of Carcinus maenas prefer the upper shore, but such behaviour could serve as a mechanism of avoiding intra- and interspecific predation since the smallest crabs of less than $5 \mathrm{~mm}$ carapace width are particularly vulnerable to predators (Moksnes et al. 1998). Although some 
A.
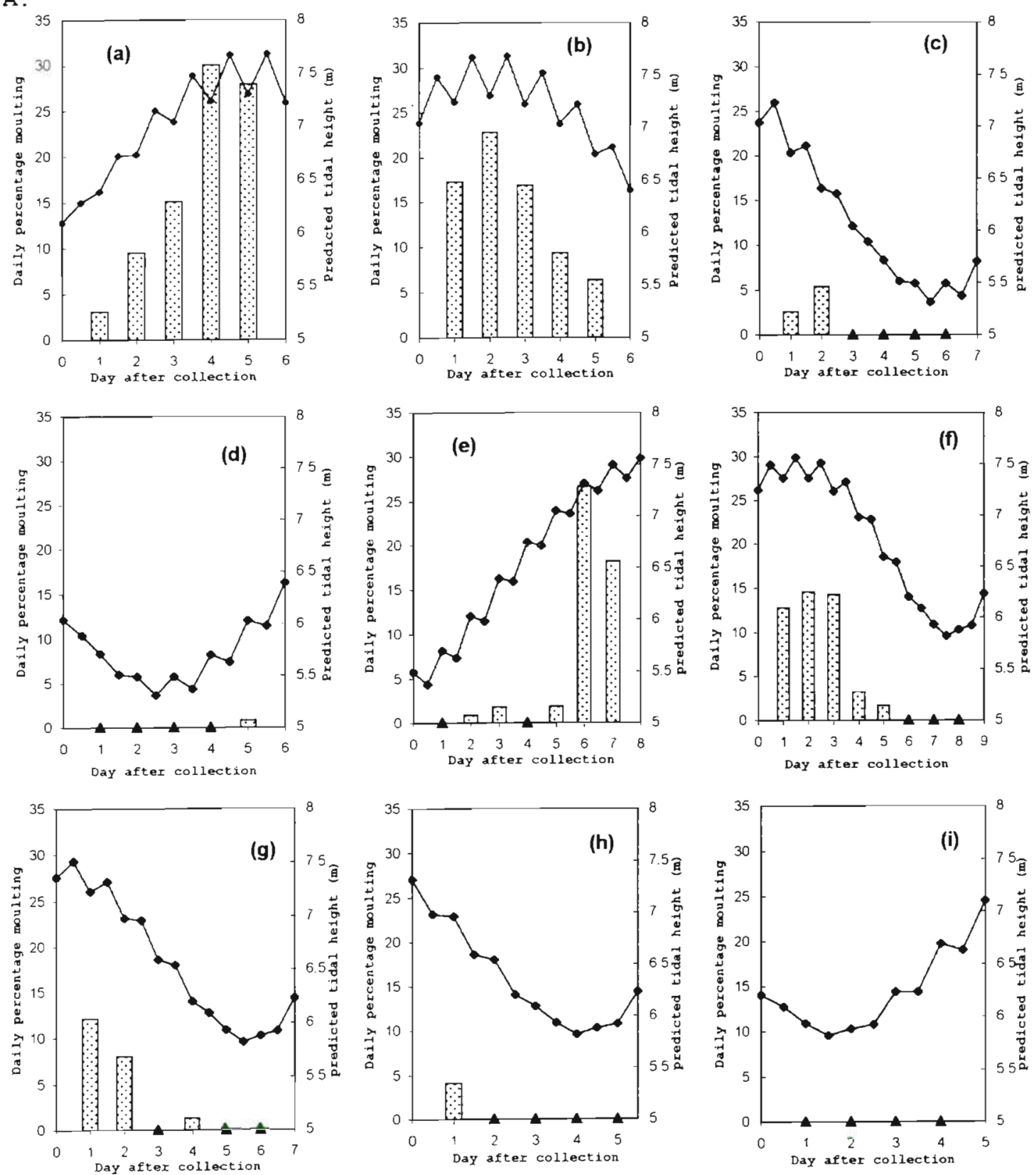

B.

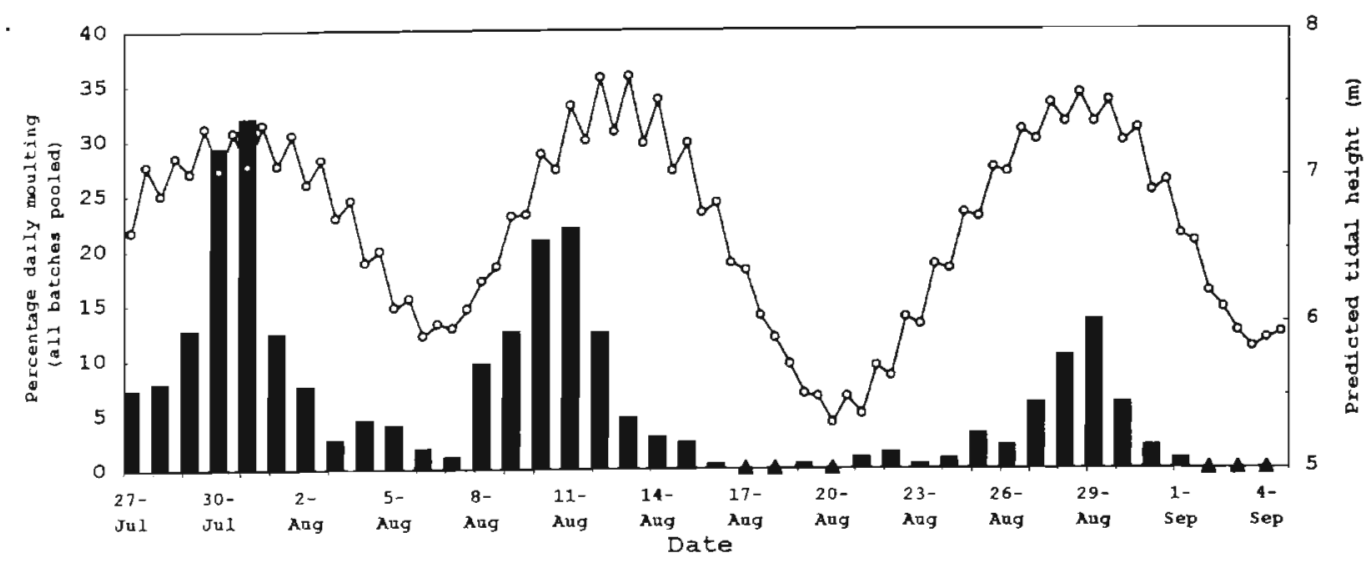


Fig. 4. Carcinus maenas. (A) Daily percentage moulting (histograms) for 5 to 8 consecutive days after collection in 9 batches of first and second instar crabs, freshly collected from the high intertidal at intervals of a few days in August and September 1995 . Lines represent the predicted tidal heights of high tides over the observation periods. Triangles on $x$-axis: no moulting took place on these days. (a) Crabs collected on 7 August during neap-to-spring increasing tidal amplitudes. Experiment started at 15:30 h with ecdysis of 98 crabs being monitored for 5 consecutive days. (b) Crabs collected on 10 August at the beginning of a period of spring tides. Experiment started at $18: 30 \mathrm{~h}$ with ecdysis of $260 \mathrm{crabs}$ being monitored for 5 consecutive days. (c) Crabs collected on 14 August during spring-to-neap decreasing tide amplitudes. Experiment started at 18:30 h with ecdysis of 114 crabs being monitored for 6 consecutive days. (d) Crabs collected on 17 August, just before a period of minimal neap tides. Experiment started at $09: 00 \mathrm{~h}$ with ecdysis of 122 crabs being monitored for 5 consecutive days. (e) Crabs collected on 20 August during tidal amplitudes increasing from a minimal neap tide. Experiment started at 11:00 h with ecdysis of $110 \mathrm{crabs}$ being monitored for 7 consecutive days. (f) Crabs collected on 27 August at the beginning of a period of spring tides. Experiment started at 18:00 h with ecdysis of $95 \mathrm{crabs}$ being monitored for 8 consecutive days. (g) Crabs collected on 29 August during spring-to-neap decreasing tidal amplitudes. Experiment started at 19:30 h with ec-dysis of $98 \mathrm{crabs}$ being monitorec for 6 consecutive days. (h) Crabs collected on 31 August during spring-to-neap decreasing tidal amplitudes. Experiment started at 10:30 h with ecdysis of 97 crabs being monitored for 5 consecutive days. (i) Crabs collected on 2 September at the beginning of a period of minimal neap tides. Experiment started at 11:00 $\mathrm{h}$ with ecdysis of 95 crabs being monitored for 4 consecutive days. (B) Pooled daily percentage moulting (histograms) between 27 July and 4 September 1995 from all 23 crab batches. The pooled percentages were calculated by adding together all daily moulting numbers from the different batches available on each day and then dividing by the total crab number from those batches. Only those moulting within 5 days of collection were used since moulting of a single crab batch was mostly observed for 5 consecutive days. Line represents predicted tidal maxima over the period. Triangles on $x$-axis: no moulting occurred on these days

foraging fish and crustaceans, including older conspecific C. maenas (Klein-Breteler 1976, Reid et al. 1993, Warman et al. 1993, Thiel \& Dernedde 1994), traverse the intertidal zone with the incoming tides, large predatory fishes, at least, do not normally advance into very shallow water at the tidal edge (pers. obs.). Hence predator encounters with small C. maenas are likely to be less frequent than if the young crabs occurred downshore. It has also been reported that in non-vegetated estuaries, inter- and intraspecific size segregation occurred by depth in various epibenthic crustaceans, and mortality of the small blue crab Callenectes sapidus increased significantly with depth (Ruiz et al. 1993). In addition, debris carried by incoming tides probably provides a rich source of food high up on the shore, and by sheltering under gravel or burying in the substrate, young crabs would reduce the risks of desiccation. However, despite all the possible advantages, inhabiting the high intertidal also presents challenges to the young crabs with respect to the process of ecdysis. If external physical factors are not optimal, the individual may be unable to complete its moult and will die before leaving its old carapace (Conan 1985). During ecdysis, a marine decapod crustacean such as $C$. maenas needs to take up water to expand its new soft exoskeleton (Bliss 1990, Chang 1995). Also since marine decapods lose most (ca $90 \%$ ) of their body calcium during ecdysis, they must obtain the bulk of their calcium requirement (ca 95\%) from the seawater to accomplish new exoskeleton calcification (Robertson 1960, Greenway 1983, 1985). Since the high intertidal habitat of early juvenile $C$. maenas is characterized by being immersed only during certain periods of tidal and neap-spring cycles, it would not be surprising if selection pressures for such crabs favoured rhythmic patterns of moulting at high tide, particularly at spring tides.

The present results suggest that ecdysis of early juvenile Carcinus maenas in the field does take place at the time when their habitat is inundated. This is achieved not simply in response to inundation but also by the crabs possessing an endogenous circatidal ecdysis rhythm of high tide moulting with a circasemilunar moulting rhythm superimposed on it. Under constant conditions in the laboratory, the moulting of the early juvenile crabs was shown to concentrate at expected maximal spring tides when their high intertidal habitat would be immersed for a substantial period. When tidal amplitude declines toward expected neap tides, moulting frequency of the crabs decreased sharply; any moulting which did occur again took place at expected high tides. At the expected times of neap high tides very little moulting took place (Figs. 3a \& 4). The present results suggest that for the study area a high tide height of about $6.0 \mathrm{~m}$ is critical; among crabs collected on days of high tide height lower than $6.0 \mathrm{~m}$, moulting rarely took place (Figs. 3a \& 4).

It is well known that under constant conditions, lacking continuous entrainment by environmental cues, an endogenous rhythm of an individual animal free-runs with a periodicity shorter or longer than the rhythm expressed in nature. As a result, biological rhythms derived from a population of animals in the laboratory are likely to gradually lose their synchrony and finally become random because the periodicities exhibited by various individuals progressively drift out of phase. It is also often the case that in a population of animals a certain proportion are arrhythmic under constant conditions (Gibson 1976, Reid \& Naylor 1989). For these reasons, the moulting rhythms studied, as here, by population analysis would be expected to show some 
desynchronization after several days of observation in the laboratory constant conditions (Fig. 1). Clearly, if endogenous circatidal and circasemilunar rhythms of moulting have been selected for in juvenile Carcinus maenas, as the present results suggest, then further studies on the physiological basis of such rhythms should be carried out in the context of the current state of knowledge of endocrine regulation of the physiological and biochemical changes that occur during the moulting cycle of such crabs (Skinner 1985, Chang 1989, 1993, 1995).

Previous research on temporal patterns of moulting have put most emphasis on long-term seasonal moulting, ecdysis patterns of shorter period receiving less attention (see review by Conan 1985). Yet most such studies have been carried out in the field or under light/dark cycles in the laboratory, with only a few of them having been undertaken with animals in constant conditions in which endogenous control of moulting rhythms could be confirmed (Fowler et al. 1971, Bishop \& Herrnkind 1976, Nicol 1989, Fernandez et al. 1994). Although crustacean moulting rhythms of lunar (29.7 d), semilunar (14.7 d) and diel (24 h) periodicity have been described previously, it was not until recently that true circatidal moulting rhythms $(12.4 \mathrm{~h})$ were first demonstrated (Abello et al. 1997, Zeng et al. 1997). The circatidal moulting rhythms of Carcinus maenas early juveniles found in the present study, together with those reported earlier for megalopae (Zeng et al. 1997) and adult females (Abello et al. 1997) of the same crab species, now provide substantial evidence for true circatidal timing mechanisms controlling moulting in this species. On the other hand, circasemilunar moulting rhythms have been documented previously in several taxonomic groups, including caridean shrimps and mysids (Nouvel 1945), stomatopods (Reaka 1976), isopods (Klapow 1972) and amphipods (Williams 1979), though the phasing of such rhythms often differs from that of the juvenile $C$. maenas in the present study. For example, Williams (1979) reported synchronous moulting of 5 to $7 \mathrm{~d}$ prior to full/new moon in the amphipod Talitrus saltator. Nevertheless, the coupling of circatidal moulting rhythms with circasemilunar rhythms and the endogenous control of the rhythms as reported in the present study appears to have been demonstrated for the first time in a crustacean.

Hitherto, somewhat speculative generalizations have been put forward concerning the adaptive significance of moulting rhythms phased to geophysical variables. For example, diel moulting rhythms in a number of crustaceans are variously reported to be adaptive for predator avoidance (Tamm \& Cobb 1976, Fernandez et al. 1994), reduced cannibalism (Lipcius \& Herrnkind 1982, Volpato \& Hoshino 1987) and reduced competi- tion for shelter (Tamm \& Cobb 1976). Similar suggestions were inferred for semilunar moulting rhythms in stomatopods (Reaka 1976). More specifically, it has been suggested that semilunar moulting rhythms increased mating opportunity and led to minimal exposure of recently moulted individuals to wave action in amphipods that inhabit the strandline of sandy beaches (Williams 1979). For the present study, based upon observations of crabs collected at various times of the tidal and neap-spring cycles and kept subsequently in constant conditions, we suggest that the observed circatidal and circasemilunar moulting rhythms in early crabs of Carcinus maenas are adaptive to the high intertidal habitat, allowing ecdysis to take place only when the habitat is inundated.

Since there is evidence for the heritability of circatidal clock control of larval tidal vertical migration rhythms in Carcinus maenas (Zeng \& Naylor 1996d), it is not surprising to observe such rhythms expressed in the ecdysis process of juveniles of this species. Synchronization of the circatidal locomotor rhythm of adult C. maenas and other crustaceans has been well documented; it occurs in response to cyclic changes of turbulence, hydrostatic pressure, salinity, temperature and immersion/emersion (Enright 1965b, 1974, Naylor \& Atkinson 1972, Taylor \& Naylor 1977, DeCoursey 1983, Naylor \& Williams 1984, Bolt \& Naylor 1985, Reid et al. 1993). For circasemilunar rhythms, the synchronization process is much less studied. Benson (1977) suggests that periodic, small-scale changes in daily mean water temperature caused by an interaction of tidal cycles and daily variations of solar radiation may entrain the semilunar rhythm of Talitrus quoyana. Also Enright (1972) proposed that an endogenous, circalunar rhythm in Excirolana chiltoni was synchronized by wave-generated substrate agitation and vibration correlated with tidal height. Synchronizers of the circasemilunar moulting rhythms in C. maenas juvenile crabs have yet to be elucidated, but the environmental variables mentioned above could be candidates. However, as the duration of first instar crabs normally lasts for only about $1 \mathrm{wk}$, it is unclear how a circasemilunar timing is set in phase with local tides, since the newly settled crabs are unlikely to have experienced a full spring-neap cycle in the high intertidal before their first moult. One possibility is that the rhythms are entrained at the megalopa stage, since in our earlier work we have suggested that semilunar recruitment and settlement rhythms occur in C. maenas megalopae (Zeng et al. 1997), but further investigation of this phenomenon is required.

Finally, the cellular and molecular bases of timing mechanisms governing circatidal and circasemilunar rhythms have been less extensively studied then those of circadian systems. Indeed, recent intensive debate 
has focussed on whether circatidal rhythms are driven by 2 lunar-day oscillators coupled in antiphase (Palmer 1995b, 1997) or by true circatidal physiological oscillators (Naylor 1996, 1997). Since the nature of crustacean moulting hormones and their regulating pathways have been well studied (Skinner 1985, Chang 1989, 1993, 1995), further investigation of moulting endocrinology in the context of present findings could lead to useful contributions to that debate.

Acknowledgements. This work was carried out during a Chinese/British Technical Cooperation PhD studentship to C.Z.; P.A. was partly supported by CSIS, Barcelona, Spain. We thank anonymous reviewers for constructive comments that improved the manuscript.

\section{LITERATURE CITED}

Aargard A, Warman CG, Depledge MH, Naylor E (1995) Dissociation of heart rate and locomotor activity during the expression of rhythmic behaviour in the shore crab Carcinus meanas. Mar Freshw Behav Physiol 26:1-10

Abello P. Warman CG, Naylor E (1997) Circatidal moulting rhythm in the shore crab Carcinus maenas. J Mar Biol Assoc UK 77:277-280

Albrecht A, Reise K (1994) Effects of Fucus vesiculosus covering intertidal beds in the Wadden sea. Helgol Wiss Meeresunters 48:243-256

Benson JA. (1977) Entrainment of a circadian rhythm of activity in an amphipod by skeleton photoperiods. J Interdisc Cycle Res 8:37-45

Berril M (1982) The life cycle of the green crab Carcinus maenas at the northern end of its range. J Crustac Biol 2.31-39

Bishop JM, Herrnkind WF (1997) Burring and molting of pink shrimp, Penaeus duorarum (Crustacea: Penaeidae), under selected photoperiods of white and UV-light. Biol Bull 150: $153-182$

Bliss DE (1990) Shrimps, lobsters and crabs. Columbia University Press, New York

Bolt SRL, Naylor E (1985) Interaction of endogenous and exogenous factors controlling the activity rhythms in Carcinus maenas. J Exp Mar Biol Ecol 85:47-56

Chang ES (1989) Endocrine regulation of moulting in Crustacea. Rev Aquat Sci 1:131-157

Chang ES (1993) Comparative endocrinology of moulting and reproduction: insects and crustaceans. Annu Rev Entomol $33: 161-180$

Chang ES (1995) Physiological and biochemical changes during the molt cycle in decapod crustaceans: an overview. $\checkmark$ Exp Mar Biol Ecol 193:1-14

Cohen AN, Carlton JT, Fountain MC (1995) Introduction, dispersal and potential impacts of the green crab Carcinus maenas in San Francisco Bay, California. Mar Biol 122: $225-238$

Conan GY (1985) Periodicity and phasing of moulting. In Wenner AM (ed) Crustacean issues, Vol 3. Factors on adult growth. Balkema Press, Rotterdam, p 73-99

Crothers JH (1968) The biology of the shore crab Carcinus maenas. 2. The life of the adult crab. Field Stud 2:579-614

DeCoursey PJ (1983) Biological timing. In: Bliss DE, Mantele LH (eds) The biology of Crustacea, Vol 7. Academic Press, New York, p 107-162

Enright JT (1965a) The search for rhythmicity in biological time-series. J Theor Biol 8:426-468
Enright JT (1965b) Entrainment of a tidal rhythm. Science $147: 864-867$

Enright JT (1972) A virtuoso isopod: circa-lunar rhythms and their tidal fine structure. J Comp Physiol 77:141-162

Enright JT (1974) Orientation in time:endogenous clocks. In: Kinne $O$ (ed) Marine ecology, Vol 2. Wiley Interscience, New York, p 467-494

Fernandez M, Iribarne O, Armstrong D (1994) Ecdysial rhythms in megalopae and first instar of the Dungeness crab Cancer magister. Mar Biol 118:611-615

Fowler SW, Small LF, Keckes S (1971) Effects of temperature and size on moulting of euphausiid crustaceans. Mar Biol 11:45-51

Gibson RN (1976) Comparative studies on the rhythms of juvenile flatfish. In: DeCoursey PJ (ed) Biological rhythms in the marine environment (Belle Baruch Library in Marine Science No. 4). Univ of South Carolina Press, Columbia, p 169-186

Greenway P (1983) Uptake of calcium at the postmoult stage by the marine crabs Callinectes sapidus and Carcinus maenas (L.). Comp Biochem Physiol 75A:181-184

Greenway P (1985) Calcium balance and moulting in the Crustacea. Biol Rev 60:425-454

Grosholz ED, Ruiz GM (1995) Spread and potential impact of the recently introduced European green crab, Carcinus maenas, in central California. Mar Biol 122:239-248

Hunter E, Naylor E (1993) Intertidal migration by the shore crab Carcinus maenas. Mar Ecol Prog Ser 101:131-138

Klapow LA (1972) Fortnightly moulting and reproductive cycles in the sand beach isopod, Erocirolana chiltoni. Biol Bull 143:568-591

Klein-Breteler WCM (1976) Migration of the shore crab, Carcinus maenas, in the Dutch Wadden sea. Neth J Sea Res 10:354-376

Lipcius RN, Herrnkind WF (1982) Moult cycle alterations in behaviour, feeding and diel rhythms of a decapod crustacean, the spiny lobster Panulirus argus. Mar Biol 68:241-252

Moksnes PO, Phil L, van Montfrans J (1998) Predation on postlarvae and juveniles of the shore crab Carcinus maenas: importance of shelter, size and cannibalism. Mar Ecol Prog Ser 166:211-225

Naylor E (1985) Tidally rhythmic behaviour of marine animals. Symp Soc Exp Biol 39:63-93

Naylor E (1996) Crab clockwork: the case for interactive circatidal and circadian oscillators controlling rhythmic locomotor activity of Carcinus maenas. Chronobiol Int 13: $153-161$

Naylor E (1997) Crab clocks rewound. Chronobiol Int 14(4): $427-430$

Naylor E, Atkinson RJA (1972) Pressure and the rhythmic behaviour of inshore marine animals. Symp Soc Exp Biol 26:395-415

Naylor E. Williams BG (1984) Environmental entrainment of tidally rhythmic behaviour in marine animals. Zool J Limn Soc 80:201-208

Nicol S (1989) Apparent independence of the spawning and moulting cycles in female Antarctic Krill (Euphausia superba Dana). Polar Biol 9:371-375

Nouvel H (1945) Les relations entre la périodicité lunaire les marées et la mue des crustacés. Bull Inst Océanogr 879:1-4

Palmer JD (1995a) The biological rhythms and clocks of intertidal animals. Oxford University Press, New York

Palmer JD (1995b) Review of dual-clock control of tidal rhythms and the hypothesis that the same clock governs both circatidal and circadian rhythms. Chronobiol Int $12(5): 299-310$ 
Palmer JD (1997) Dueling hypotheses: circatidal versus circalunindian battle basis. Chronobiol Int 14(4):337-346

Queiroga H, Costlow JD, Moreira MH (1997) Vertical migration of the crab Carcinus maenas first zoea in an estuary: implications for tidal stream tranport. Mar. Ecol Prog Ser 149:121-132

Reaka ML (1976) Lunar and tidal periodicity of molting and reproduction in stomatopod crustacea: a selfish herd hypothesis. Biol Bull 150:468-490

Reid DG, Naylor E (1989) Are there separate circatidal and circadian clocks in the shore crab Carcinus maenas? Mar Ecol Prog Ser 52:1-6

Reid DG, Warman CG, Naylor E (1993) Ontogenetic changes in zeitgeber action in the tidally rhythmic behaviour of the shore crab Carcinus maenas. In: Aldrich JC (ed) Quantified phenotypic responses in morphology and physiology Proc 27th Eur Mar Biol Symp. JAPAGA, Dublin, p 129-133

Robertson JD (1960) Ionic regulation in the crab Carcinus maenas (L.) in relation to the moulting cycle. Comp Biochem Physiol 1:183-212

Ruiz GM, Hines A., Posey MH (1993) Shallow water as a refuge habitat for fish and crustaceans in non-vegetated estuaries: an example from Chesapeake Bay. Mar Ecol Prog Ser 99:1-16

Skinner DM (1985) Moulting and regulation. In: Bliss DE, Mantele LH (eds) The biology of Crustacea, Vol 9. Academic Press, New York, p 43-14.6

Tamm GR, Cobb JS (1976) Diel ecdysis rhythms in juvenile lobsters Homarus americanus. J Fish Res Bd Can 33: $819-821$

Taylor AC, Naylor E (1977) Entrainment of the locomotor rhythm of Carcinus maenas by cycles of salinity change. J Mar Biol Assoc UK 57:273-277

Thiel M, Dernedde T (1994) Recruitment of shore crabs Carcinus maenas on tidal flats: mussel clumps as an important refuge for juveniles. Helgol Wiss Meeresunters 48: 321-332

Volpato GL, Hoshino L (1987) Diurnal or nocturnal ecdysis

Editorial responsibility: Otto Kinne (Editor),

Oldendorf/Luhe, Germany determined by populational factors in the freshwater prawn Macrobrachium iheringi (Ortmann 1897). Bio Hisio Animal Sao Paulo 11:113-121

Warman CG, Reid DG, Naylor E (1993) Variation in the tidal migratory behaviour and rhythmic light responsiveness in the shore crab, Carcinus maenas. J Mar Biol Assoc UK 73: $355-364$

Wheatly MG (1997) Crustacean modules for studying calcium transport: the journey from whole organisms to molecular mechanisms. J Mar Biol Assoc UK 77:107-125

Williams JA (1979) A semi-lunar rhythm of locomotor activity and moult synchrony in the sand-beach amphipod Talitrus saltator. In: Naylor E, Hartnoll RG (eds) Cyclic phenomena in plant and animals. Pergamon Press, Oxford, p 407-414

Williams JA, Naylor E (1978) A procedure for the assessment of significance of rhythmicity in time-series data. J Chronobiol 5:435-444

Zeng C, Naylor E (1996a) Endogenous tidal rhythm of vertical migration in field collected zoea-1 larvae of Carcinus maenas: implications for ebb-tide offshore dispersal. Mar Ecol Prog Ser 132:71-82

Zeng C, Naylor E (1996b) Occurrence in coastal waters and endogenous tidal swimming rhythms late megalopae of the shore crab Carcinus maenas: implications for onshore recruitment. Mar Ecol Prog Ser 136:69-79

Zeng C, Naylor E (1996c) Synchronization of endogenous tidal vertical migration rhythms in laboratory-hatched larvae of the crab Carcinus maenas. J Exp Mar Biol Ecol 198:269-289

Zeng C, Naylor E (1996d) Heritability of circatidal vertical migration rhythms in zoea larvae of the shore crab Carcinus maenas. J Exp Mar Biol Ecol 202:239-257

Zeng C, Naylor E (1997) Hatching rhythms in the shore crab Carcinus maenas (Decapoda: Brachyura). J Mar Biol Assoc UK 77:451-461

Zeng C. Naylor E, Abello P (1997) Endogenous control of timing of metamorphosis in megalopae of the shore crab Carcinus maenas. Mar Biol 128:299-305

Submitted: December 14, 1998; Accepted: July 13, 1999 Proofs received from author(s): December 7, 1999 